\title{
Biology of barley shoot fly Delia flavibasis Stein (Diptera: Anthomyiidae) on resistant and susceptible barley cultivars
}

\author{
Muluken Goftishu • Tadele Tefera • \\ Emana Getu
}

Received: 20 June 2007/Revised: 9 September 2008/Accepted: 24 September 2008/Published online: 31 October 2008 (C) Springer-Verlag 2008

\begin{abstract}
The biology of barley shoot fly Delia flavibasis was studied using resistant (Dinsho and Harbu) and susceptible (Holker) barley cultivars at Sinana Agricultural Research Center, Ethiopia. A higher number of eggs was laid on Holker (17 eggs/female) than on Dinsho (11 eggs/female) or Harbu (12 eggs/female). However, there were no differences between cultivars in preoviposition and total reproductive periods. The shortest time required to complete larval, pupal and total developmental stages from egg to adult emergence occurred when the insect was reared on the cultivar Holker. Pupal weight, adult emergence and adult longevity did not differ between cultivars. The female to male sex ratio was $1: 1$. This study enabled us to understand the duration of each of the life stages of $D$. flavibasis, which will undoubtedly aid researchers and growers to design a sustainable management strategy against barley shoot fly.
\end{abstract}

Communicated by M. Traugott.

M. Goftishu - T. Tefera

Department of Plant Sciences, Haramaya University,

P. O. Box 138, Dire Dawa, Ethiopia

E. Getu

Department of Biology, Addis Ababa University,

P. O. Box 1176, Addis Ababa, Ethiopia

Present Address:

T. Tefera $(\bowtie)$

Division of Entomology, Department of Crop Science,

Georg-August-University Goettingen, Grisebachstr. 6,

37077 Göttingen, Germany

e-mail: tadeletefera@yahoo.com
Keywords Barley - Delia flavibasis - Life cycle . Pest management $\cdot$ Resistant cultivar

\section{Introduction}

Two barley shoot fly species Delia arambourgi Seguy (Davidson 1969) and D. flavibasis Stein (Tafa 2003) are known to occur in Ethiopia, inflicting considerable yield losses. Both species belong to the order Diptera and family Anthomyiidae. Delia flavibasis has recently been recorded from Ethiopia (Tafa et al. 2004). Delia flavibasis is reported as a major pest of barley (Horedum vulgare L.) in Ethiopia and Kenya (Macharia and Mueke 1986; Tafa 2003). Infestation level of D. flavibasis in Bale highlands, Ethiopia, frequently reaches $100 \%$ on susceptible barley cultivars and causes considerable yield loss. Because of its devastating effect especially on malt barley, improved cultivars and exotic germplasms, the pest has become a major constraint to barley cultivation in the Bale highlands of Ethiopia (Amare 1993; Tafa et al. 2004).

Besides the main host barley, shoot fly survives on several alternative hosts in the grass family, like maize (Zea mays), wheat (Triticum spp.), blurish millet (Pennisetum americanum) and a few grasses (Hill 1987). Host preference study of $D$. flavibasis conducted at the Sinana Agricultural Research Center (SARC) with barley, teff, wheat, oat and maize revealed that barley and teff were the most preferred (SARC 2004).

Studies conducted on this pest focused on management aspects, viz., cultural, chemical, host plant resistance and the resistance mechanisms (Thewodros 1982; Hussien et al. 1993; Berhane et al. 1996; Tafa 2003; SARC 2004). However, information on life cycle, nature of attack and over seasoning or diapausing, which are essential for 
making decisions concerning D. flavibasis, are lacking. Such information is imperative for developing a sound strategy for shoot fly management. This study, therefore, reports on the fecundity and phenology of D. flavibasis under laboratory and field conditions.

\section{Materials and methods}

Fecundity

The fecundity of D. flavibasis was studied on a susceptible barley cultivar, Holker, and two relatively resistant cultivars, Dinsho and Harbu (SARC 2004). The resistant cultivars were food barley developed by the SARC, Ethiopia, from the Ethiopian barley landraces. Holkar is an introduced improved malt barley cultivar and is susceptible to the pest. Barley seedlings with dead hearts as a result of D. flavibasis infestation were collected from the field and kept in cages in the laboratory until the emergence of adult flies. A pair of newly emerged flies, $24 \mathrm{~h}$ old, were released into individual cages ( 30 by 20 by $20 \mathrm{~cm}$ ) having five newly emerged seedlings per cage of 1.1-growth stage (first leaf unfolded) (Zadoks et al. 1974) for oviposition. The cage had a plastic cover with a plastic mesh in the middle to allow air circulation. The cages were arranged in a completely randomized block design with five replications. Adults were provided with diet prepared from glucose, brewers yeast and distilled water at the ratio of 4:7:10, respectively (Kasana and AliNiazee 1994). Cages were examined two times daily (in 12-h interval) to determine preoviposition period, number of eggs per female and total reproductive period. Data were recorded on days to oviposition, total number of eggs per day and total reproductive period. Eggs were removed at each time of data collection.

Laboratory and field phenology of D. flavibasis

\section{Egg stage}

The developmental period of D. flavibasis was studied on susceptible barley cultivar, Holker, and two relatively resistant cultivars, Dinsho and Harbu. For this study, freshly laid eggs, age less than $24 \mathrm{~h}$, were collected from the field and transferred to individual seedlings in pots $\left(25 \mathrm{~cm}\right.$ in diameter) in the laboratory $\left(21-23^{\circ} \mathrm{C}\right)$. Twelve seedlings of each of the three cultivars were raised in each pot and thinned to ten before egg inoculation. Each seedling was inoculated with two eggs of $D$. flavibasis by placing them at the base of each plant at 1.1-growth stage (Zadoks et al. 1974). This was done using sterile camel hair brush (Delobel and Unnitahn 1983; Ortega et al. 1980).
The pots were arranged in a completely randomized block design with four replications. A fluorescent lamp was hung above the rearing pots and artificial light was supplemented for $12 \mathrm{~h}$ daily during the experimental period. A total of 80 eggs were used for each cultivar both in the laboratory and in the field. The same experiment was repeated in the field. In the field, the pots were housed in screen cage ( 41 by 50 by $60 \mathrm{~cm}$ ) made of wooden frame covered with white muslin cloth to protect from oviposition by the adult fly. Seedlings were examined four times at 4-h interval per day to observe egg hatching. Data on the number of hours required for hatching was recorded.

\section{Larval stage}

After egg hatching, the duration of larval development was assessed on the three barley cultivars in the pot experiment. A total of 56 and 52 larvae on each cultivar were used for the laboratory and field experiments, respectively. Observations were made four times daily at for hour interval until prepupation commenced and the total number of days to pupation recorded.

\section{Pupal stage}

To determine prepupal (last larval instar becomes inactive, stop feeding, leaves the seedling and burirs itself in the soil) and pupal developmental time, seedlings of the three barley cultivars with dead hearts having last larval instar of $D$. flavibasis were carefully uprooted. The prepupae were placed in moistened soil in a $14 \mathrm{~cm}$ diameter Petri dish and kept at room temperature in the laboratory $\left(20-23^{\circ} \mathrm{C}\right)$ and in the screen cage in the field. The purpose of adding soil to petridishes was to provide the pupae with suitable conditions similar to the natural habitat (Bullock 1965). A completely randomized block design with four replications was used. Observations were made on 48 and 40 pupae collected from each cultivar both in the laboratory and in the field, respectively. Each petridish was examined four times per day at 4-h interval. Records were taken on prepupal and pupal developmental time and pupal weight. Pupae were weighed using WA 80 analytical electronic balance having sensitivity of $80 / 0.0001 \mathrm{~g}$. All pupae were weighed and carefully returned to the respective Petri dishes in the soil to determine adult emergence.

\section{Adult stage}

To determine adult emergence period, pupae were collected from each Petri dish of each cultivar and kept in rearing cages ( 30 by 20 by $20 \mathrm{~cm}$ ). A completely randomized block design with four replications was used. 
Observations were made on 36 and 28 flies on each cultivar in the laboratory and in the field, respectively. Each cage was examined four times daily at 4-h intervals until adult flies emerge. At emergence, adults were carefully removed using siphon trap and were placed in another cage. The flies were provided with diets prepared from glucose, brewers yeast and distilled water at the ratio of 4:7:10, respectively (Kasana and AliNiazee 1994). Data were recorded on adult emergence and longevity period of adult flies.

\section{Statistical analysis}

Data on the time required for preoviposion, total reproduction, egg hatching, larval stage, pupal stage, adult emergence, longevity, total developmental time and pupal weight were subjected to analysis of variance (ANOVA). Number of eggs per female was transformed using square root $(\sqrt{\mathrm{X}+0.5})$ to stabilize the variance before being subjected to ANOVA. Whenever the $F$ test was significant $(P<0.05)$, least significant difference (LSD) was used for mean separation. Data were analyzed using a general linear model (PROC GLM, SAS Institute 1999-2000).

\section{Results}

Fecundity of D. flavibasis

As observed in the laboratory and in the field, eggs may be found laid singly or in groups. There were significant differences $(P<0.05)$ in number of eggs oviposited between the barley cultivars. The highest number of eggs (17.9) was laid on the susceptible cultivar, Holker, and the least on Harbu (12.3) and Dinsho (11.5) (Table 1). However, no significant differences were observed between cultivars in preovipostion and total reproductive periods. The egg of D. flavibasis is white and elongate-

Table 1 Mean + SE number of eggs, preovipositon period and total reproductive period of Delia flavibasis on three barley varieties in the laboratory

\begin{tabular}{llll}
\hline Variety & $\begin{array}{l}\text { Number of } \\
\text { eggs/female }\end{array}$ & $\begin{array}{l}\text { Preoviposition } \\
\text { period (days) }\end{array}$ & $\begin{array}{l}\text { Total reproductive } \\
\text { period (days) }\end{array}$ \\
\hline Dinsho & $11.50 \pm 2.33 \mathrm{~b}$ & $3.53 \pm 0.24$ & $5.03 \pm 0.20$ \\
Harbu & $12.33 \pm 2.78 \mathrm{~b}$ & $3.50 \pm 0.22$ & $5.02 \pm 0.24$ \\
Holker & $17.90 \pm 2.62 \mathrm{a}$ & $3.50 \pm 0.31$ & $5.35 \pm 0.22$ \\
LSD & 4.42 & NS & NS
\end{tabular}

Means within a column followed by the same letter are not significant at $P<0.05$

NS not siginificant ovoid in shape, resembling grains of rice. It has longitudinal ridges or strips when observed under a microscope.

Phenology of D. flavibasis

Egg stage

Significant difference $\left(P<0.05, d f=2, \quad F_{\text {value }}=5.79\right)$ was observed in the time needed for egg hatching between the cultivars (Table 2) in the laboratory experiment. A shorter time from egg to larval stage was required for the cultivar Holker than for Dinsho or Harbu.

\section{Larval stage}

The number of days required for the development of larvae varied significantly $\left(P<0.05, d f=2, \quad F_{\text {value }}=12.18\right)$ among cultivars (Table 2). Larvae required a shorter time to reach the prepupal stage on the susceptible cultivar than on the resistant cultivars under both laboratory and field condition.

\section{Pupal stage}

The number of days required for prepupal and pupal stages on Holker was higher (2.26 days) than that on Harbu and Dinsho under laboratory condition (Table 2). However, in the field, significantly fewer days were required to reach the pupal stage on Holker than on Harbu and Dinsho. There was no difference among cultivars in pupal weight under both laboratory and field conditions. Puparia, formed of the hardened larval skin as a protective container for the pupae, were ovoid in shape. Newly formed pupae were light brown in color and slowly turned to dark brown with age. Pupation took place in the soil within $1-3 \mathrm{~cm}$ depth amongst the roots. Observation under field conditions showed that, in rare cases, pupation also took place inside the basal stalk of barley. In the present study, no evidence of diapause was obtained; all larvae and pupae, which were reared in the laboratory, completed their cycle without interruption, which indicates that D. flavibasis did not diapause at the immature stages.

\section{Adult stage}

Adult emergence and longevity required 7-9 days and were not affected by cultivars under either laboratory or field conditions (Table 2). The total developmental period (from egg to adult 10 emergence) was significantly $\left(P<0.05, d f=2, F_{\text {value }}=14.43\right)$ shorter on the susceptible cultivar compared to the resistant cultivars in the laboratory and field. 
Table 2 Developmental time of Delia flavibasis and adult longevity on three barley varieties (mean + SE) in the laboratory and field

\begin{tabular}{lllllllll}
\hline Variety & $\begin{array}{l}\text { Egg hatching } \\
(\mathrm{h})\end{array}$ & $\begin{array}{l}\text { Larval stage } \\
\text { (days) }\end{array}$ & $\begin{array}{l}\text { Prepupal } \\
\text { stage (days) }\end{array}$ & $\begin{array}{l}\text { Pupal stage } \\
\text { (days) }\end{array}$ & $\begin{array}{l}\text { Pupal } \\
\text { weight }\end{array}$ & $\begin{array}{l}\text { Adult } \\
\text { emergence } \\
\text { (days) }\end{array}$ & $\begin{array}{l}\text { Adult } \\
\text { longevity } \\
\text { (days) }\end{array}$ & $\begin{array}{l}\text { Total time } \\
\text { (egg-adult } \\
\text { emergence) }\end{array}$ \\
\hline Laboratory experiment & & & & & & & \\
Dinsho & $74.45 \pm 4.12 \mathrm{a}$ & $13.14 \pm 1.81 \mathrm{a}$ & $1.68 \pm 0.21 \mathrm{~b}$ & $13.81 \pm 1.52 \mathrm{a}$ & $3.20 \pm 0.31$ & $8.81 \pm 1.25$ & $8.61 \pm 2.01$ & $40.54 \pm 4.01 \mathrm{a}$ \\
Harbu & $77.59 \pm 6.04 \mathrm{a}$ & $12.60 \pm 1.52 \mathrm{a}$ & $1.61 \pm 0.32 \mathrm{~b}$ & $13.58 \pm 1.81 \mathrm{a}$ & $3.15 \pm 0.29$ & $8.54 \pm 1.48$ & $8.54 \pm 1.80$ & $39.56 \pm 3.42 \mathrm{a}$ \\
Holker & $68.40 \pm 3.01 \mathrm{~b}$ & $11.35 \pm 1.05 \mathrm{~b}$ & $2.26 \pm 0.55 \mathrm{a}$ & $11.94 \pm 1.03 \mathrm{~b}$ & $3.48 \pm 0.34$ & $8.41 \pm 1.23$ & $8.90 \pm 2.30$ & $36.81 \pm 2.81 \mathrm{~b}$ \\
LSD & 6.72 & 0.91 & 0.30 & 0.56 & $\mathrm{NS}$ & $\mathrm{NS}$ & $\mathrm{NS}$ & 2.06 \\
Field experiment & & & & & & & \\
Dinsho & $72.43 \pm 3.52$ & $13.24 \pm 1.04 \mathrm{a}$ & $1.65 \pm 0.30$ & $13.99 \pm 2.03 \mathrm{a}$ & $3.06 \pm 0.42$ & $7.86 \pm 0.46$ & $7.37 \pm 1.48$ & $39.67 \pm 3.32 \mathrm{a}$ \\
Harbu & $75.81 \pm 5.21$ & $13.20 \pm 1.92 \mathrm{a}$ & $1.79 \pm 0.41$ & $13.60 \pm 1.82 \mathrm{a}$ & $3.20 \pm 0.23$ & $7.83 \pm 0.23$ & $7.54 \pm 1.50$ & $39.62 \pm 3.04 \mathrm{a}$ \\
Holker & $77.74 \pm 5.00$ & $12.35 \pm 0.42 \mathrm{~b}$ & $1.82 \pm 0.34$ & $11.50 \pm 0.81 \mathrm{~b}$ & $3.50 \pm 0.27$ & $7.30 \pm 0.51$ & $8.10 \pm 2.00$ & $36.21 \pm 2.40 \mathrm{~b}$ \\
LSD & $\mathrm{NS}$ & 0.74 & $\mathrm{NS}$ & 0.63 & $\mathrm{NS}$ & $\mathrm{NS}$ & $\mathrm{NS}$ & 2.83 \\
\hline
\end{tabular}

Means within a column followed by the same letter are not significant at $P<0.05$

NS not significant

\section{Discussion}

The present study demonstrated the effect of barley cultivars on D. flavibasis fecundity and phenology. The susceptible cultivar, Holker, is preferred for oviposition than Dinsho and Harbu. Tafa (2003) reported a similar trend in the egg hatching time of $D$. flavibasis on different barley cultivars inoculated with eggs of $D$. flavibasis under laboratory conditions. He found significant differences between the susceptible $(60.00 \mathrm{~h})$ and resistant $(78.00 \mathrm{~h})$ barley cultivars for the time required for egg hatching. Previous studies conducted on D. arambourgi (Bullock 1965) and D. platura (Hill 1987) indicated 72-96 h for egg hatching. Occasionally, D. flavibasis may oviposit on the undersurface of older leaves. Under normal conditions, young barley seedlings (two to three leaf stages) are most preferred for oviposition. However, oviposition can occur on tillers of older plants and their leaves. On susceptible cultivars, which are recurrently infested, oviposition lasts for a longer period. Preliminary observation made during the field study revealed that most of the adults trapped from barley seedlings and from newly ploughed lands are females. The females visit these areas probably to lay their eggs on barley seedlings and to create conducive environment for the larvae. We observed that adult $D$. flavibasis are most active during late morning (9:3010:30 am) and late afternoon (4:00-5:00 pm). Adult flies are usually found on newly ploughed moist soil and newly emerging seedlings during this time of the day.

Generally, fewer numbers of eggs were laid by $D$. flavibasis in this study as compared to 100 eggs per female by D. radicum (Hill 1987) and about 238 eggs per female by A. soccata (Sileshi and Lakra 1994). This may reflect the differences in oviposition potential among the dipteran species. Diet is also a relevant factor in variation in ovipostion. According to Jones et al. (1992), lack of protein at the adult stage is an important constraint to the reproductive success of many muscoid dipterans. McDonald and Borden (1996) found that elimination of protein from the diet of female $D$. antiqua often resulted in lower sexual attraction, reproductive competency and fecundity.

The damaging stage of $D$. flavibasis is the larval stage. Infestation commenced with a mine in the first or second leaf or both and the larvae make its way down through the tissues to the growing point. The attack results in death of the central shoot, producing dead heart. Following dead heart formation, the larvae may quit the shoots and mine through the leaves of the seedlings. In the field, the mined leaves collapse at their weakened bases, lying flat on the soil surface. Similar observations were reported by Davidson (1969) on D. arambourgi. On the other hand, Bullock (1965) observed that this type of attack by $D$. arambourgi is only occasional in Kenya. The larvae of $D$. arambourgi bore directly into the central shoot after climbing above the first leaf sheath. Field observations in the current study revealed that most of the attacked seedlings had both the first and second leaves mined. It was observed that, occasionally, a seedling may host more than one larva and the larvae may leave a seedling and bore another seedling in the vicinity. Davidson (1969) reported similar observations for $D$. arambourgi. The variations in number of days required for larval and pupal stages of $D$. flavibasis under both laboratory and field conditions between the susceptible and resistant cultivars may be attributed to the existence of antibiosis in resistant cultivars. Tafa (2003) reported antibiosis mechanism of resistance to $D$. flavibasis in different barley cultivars, viz., PGRCE/E 1799, PGRCE/E 4414, PGRCE/E 4409, PGRCE/E 4282 and Arusso to a lesser degree. 
The shortest time required to complete developmental stages from egg to adult on the susceptible cultivar, Holker, indicates the suitability of the cultivar to the shoot fly. However, owing to its high demand by malt industries in Ethiopia, Holker fetches high prices and farmers prefer to cultivate Holker than the other cultivars. Therefore, this cultivar needs to be protected against shoot fly infestation. It has been reported that one principal component of shoot fly management is adjustment of sowing dates (SARC 2004). In the region, farmers very often sow barley in the begging of June. The present study indicates that, one generation requires about 36 days on the susceptible cultivar, Holker. Hence, delayed sowing might have crop growth stages coinciding with high population levels and, consequently, infestation might increase. In spite of some degree of infestation by shoot fly, early sown barley cultivars recovered from shoot fly damage and gave relatively better yield by fully exploiting the available moisture (SARC 2004).

The present study indicates that, after egg hatching, the larvae feed on the barley shoot for 11-13 days, causing a dead heart, before they enter into the soil for pupation. Application of insecticides, if feasible, therefore, should focus on the early larval stages. The insecticides, carbofuran, aldicarb, cyfluthrin and deltamethrin are reported to be effective against the shoot fly (Thewodros 1982; Hussien et al. 1993). Information on the life cycle of barley shoot fly as determined in the current study will aid researchers and growers in designing a sustainable management strategy against this pest.

\section{References}

Amare A (1993) Infestation and damage level of barley shoot fly (Delia arambourgi) at Sinana. In: Proceedings of the Joint Conference of the Ethiopian Phytopathological Committee and the Committee of Ethiopian Entomologists, Addis Ababa, Ethiopia, 5-6 March 1992. Crop Protection Society of Ethiopia (CPSE), Addis Ababa, p 28

Berhane L, Hailu G, Fekadu A (1996) Barley production and research. In: Gebre H, van Leur (eds) Barley research in Ethiopia: past work and future prospects. Proceedings of the first barley research review workshop, Addis Ababa, Ethiopia, 16-19 October 1993. Institute of Agricultural Research (IAR), Addis
Ababa, Ethiopia/International Center for Agricultural Research in Dry Areas (ICARDA), Aleppo, Syria, pp 1-8

Bullock JA (1965) The control of Hylemya arambourgi Seguy (Diptera: Anthomyiidae) on barley. Bull Entomol Res 55:645661

Davidson A (1969) Effect of some systemic insecticides on an infestation of the barley fly Delia arambourgi in Ethiopia. East Afr Agric For J 34:422-425

Delobel AGL, Unnitahn GC (1983) Effects of constant temperature on the charactersitcs of populations of Atherigona soccata Rondani (Diptera: Muscidae). Acta Oecol Oecol Appl 4:351-368

Hill DS (1987) Agricultural insect pests of temperate regions and their control. Cambridge University Press, Cambridge, $659 \mathrm{pp}$

Hussien MLA, Melde C, Wetzel T (1993) Investigations on the effects of seed treatment of winter wheat with Decis (deltamethrin), Filitox (metamidophos) and Baythroid (cyfluthrin) against larvae of the wheat bulb fly (Delia coarctata Fall). J Phytopathol Plant Prot 28:147-154

Jones CJ, Milne DE, Patterson RS, Schreiber ET, Milio JA (1992) Nectar feeding by Stomoxys calcitrans (Diptera: Muscidae) effect on reproduction and survival. Environ Entomol 21:141147

Kasana A, AliNiazee MT (1994) Effect of constant temperature on development of the walnut hsuk fly, Rahgoletis completa. Entomol Exp Appl 73:247-254

Macharia M, Mueke JM (1986) Resistance of barley varieties to barley fly Delia flavibasis Stein (Diptera: Anthomyiidae). Insect Sci Appl 7:75-77

McDonald RS, Borden JH (1996) Dietery constraints on sexual activity, mating success, and survivorship of male Delia antiqua. Entomol Exp Appl 81:243-250

Ortega A, Vasal SK, Mihn J, Hershey C (1980) Breeding plants resistance to insects. Wiley, Chichester, $683 \mathrm{pp}$

SAS Institute (1999-2000) PROC GLM. SAS Institute, Cary, NC, 50 $\mathrm{pp}$

Sileshi G, Lakra RK (1994) Off-season survival of the sorghum shoot fly Atherigona soccata Rondani (Muscidae: Diptera) in Alemaya region of Ethiopia. Afr Crop Sci J 7:97-104

Sinana Agricultural Research Center (SARC) (2004) Entomology progress report, 1996-2004. Sinana Agricultural Research Center, Robe, Bale

Tafa J (2003) Mechanism(s) of resistance in barley accessions to shoot fly, Delia flavibasis Stein (Diptera: Anthomyiidae). MSc thesis, School of Graduate Studies of Alemaya University, 73 pp

Tafa J, Tadesse G, Sakhuja PK (2004) Ovipositional antixenosis in some barely accessions to barely shoot fly. Pest Manag J Ethiop 8:51-57

Thewodros M (1982) Studies on the sorghum shoot fly, Atherigona varia var. soccata Rondani (Diptera: Muscidae) with special reference to its biology and control measures. MSc thesis, Addis Ababa University, $88 \mathrm{pp}$

Zadoks JC, Chang TT, Konzak CF (1974) A decimal code for the growth stages of cereals. Weed Res 14:415-421 